\title{
Effects of selected factors on the osseointegration of dental implants
}

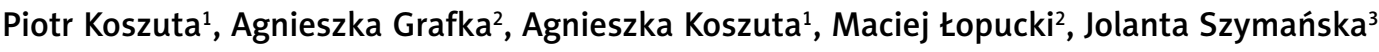 \\ 1“Dental” Non-Public Health Care Centre, Tomaszów Mazowiecki, Poland \\ ${ }^{2}$ Chair and Department of Oncological Gynaecology and Gynaecology, Medical University of Lublin, Lublin, Poland \\ ${ }^{3}$ Chair and Department of Paedodontics, Medical University of Lublin, Lublin, Poland
}

\begin{abstract}
Introduction: Osseointegration of dental implants with the maxillary and/or mandibular bone is the basis for implant prosthetic treatment. The aim of the study was to assess the influence of the patients' gender, age, and in the case of women, their menopausal status (before menopause/after menopause/during hormone replacement therapy) on the osseointegration of dental implants.

Material and methods: The study evaluated the bone loss after implant loading and the success rate of the procedure in 71 women and 30 men. In the postmenopausal group, 20 (28.1\%) women were receiving hormone replacement therapy. The implants used in the treatment of the studied patients were the two-phase dental implants. The extent of bone loss was estimated by comparing the post-implantation radiographs and the postloading ones.

Results: The implantation procedure was entirely successful in 81 patients $(80.2 \%)$. The patients' age, gender and menopausal status did not significantly affect the implantation procedure success rate or bone loss $(p>0.05)$. A correlation between bone loss and hormone replacement therapy $(p=0.002)$ was found.

Conclusions: The hormone replacement therapy contributes to a greater peri-implant bone loss. The patients receiving hormone replacement therapy who consider replacement of missing teeth with implants should be informed about a greater risk of osseointegration failure, which may affect the success of implant therapy.
\end{abstract}

Key words: dental implants, bone loss, osseointegration, menopausal status, hormone replacement therapy.

\section{Introduction}

Osseointegration is a process during which an implanted metal element fuses with the living bone. A dental implant is an artificial root-like device embedded in the bone, with a crown or a bridge attached to it. In addition, dental implants are used to support full dentures. Reactions of bone tissues responsible for proper osseointegration depend on a number of factors, mainly on the implant material and shape, local anatomical conditions in the maxilla and the mandible, and the correct performance of surgical procedures [1].

Radiography is the most common technique used to evaluate osseointegration in clinical practice. Both radiographs and clinical examination techniques enable practitioners to determine the density of peri-implant bone ( \pm radiological error); factors like implant acceptance or rejection are also taken into consideration [2].

Implant failure is defined as marked mobility of an implant or peri-implant bone loss exceeding $0.2 \mathrm{~mm}$ after the first year of implant loading [3].
The aim of the study was to evaluate the influence of gender, age and, in the case of women, their menopausal status (before/after menopause/during hormone replacement therapy [HRT]), on osseointegration of dental implants. The evaluation was based on the degree of bone loss after implant loading and the success rate of the implantation procedure.

\section{Material and methods}

The study included 71 female and 30 male patients who underwent implantation procedures in the "Dental" Health Care Centre in Tomaszów Mazowiecki between 2009 and 2012. The study design was approved by the Bioethics Committee of the Medical University of Lublin. All patients expressed in writing their informed consent to participate in the study.

Patients provided detailed information on their general health status and hormonal drugs taken. In addition, the age and menopausal status were determined for all female patients. Menopause was defined as a time of one year after the last menstruation or, in the 
case of women after hysterectomy, as 45 years of age. The mean age of women was 44.8 years $(21-67 \pm 13.5)$, whereas that of men was 44.3 years $(26-64 \pm 12.4)$.

Other possible sources of oral cavity infections were excluded: carious cavities, teeth with pulp gangrene, dental deposit, dental plaque and periodontal diseases. When preparing for the procedure, the authors looked at the quantity and quality of bone structure at the sites of planned implants (height, width of the maxillary alveolar bone or mandibular alveolar part). All patients treated with dental implants reported healthy at the time of the procedure. Each patient was informed about the stages of the treatment, its duration, and the risk of failure or possible complications.

The implants used in the therapy of the studied patients were the two-phase dental implants produced by Q-implant (Trinom Titanum, Germany), Osteoplant (Poland), Alpha-bio (Israel), MIS Implant Technologies Ltd (Israel), and certified by the Drug Institute in Warsaw. These are widely-used, screw-shaped titanium endosseous implants anchored in the bone; they are fitted with prosthetic elements in the form of abutments/ pillars to which crowns, bridges or dentures can be cemented or screwed [4].

The implantation was performed either under infiltrative or block anaesthesia, using Citocartin 100 (Molteni, Italy). The therapeutic procedure followed the routine implant-prosthetic protocol.

Panoramic radiographs were made three times: prior to making the treatment decision, immediately after the implantation and after the final loading of an implant performed on average in the $6^{\text {th }}$ month following the implantation. The latter images were compared with those taken immediately after the procedure. The extent of bone loss was estimated by comparing the post-implantation radiographs and the post-loading ones using a millimetre scale template. Bone resorption was measured from the prosthetic platform to the level of the peri-implant bone, and expressed as the percentage of bone tissue loss around an implant. For instance, using a $10 \mathrm{~mm}$ implant, the bone tissue loss of $2 \mathrm{~mm}$ was estimated as $20 \%$ bone loss.

\section{Statistical analysis}

The results were analysed statistically. The parameters on the nominal scale were characterized using the number and percentage, whereas those on the ordinal scale were characterized with arrhythmic mean and standard deviation. The differences or correlations between non-measurable parameters were determined using contingency tables and the $\chi^{2}$ independence test. Due to a non-normal distribution of the analysed variables, the Mann-Whitney $U$ test was used to detect significant differences in unpaired features for the two groups. An inference error of $5 \%$ was assumed, hence $p \leq 0.05$ was considered as statistically significant. The statistical analysis was carried out using Statistica v. 6.0 software (Statsoft, Poland).

\section{Results}

The female group comprised 45 postmenopausal patients $(63.3 \%)$ and 26 premenopausal patients (36.7\%). Among women of the postmenopausal group, $20(28.1 \%)$ had been receiving hormone replacement therapy (continuous treatment with low doses of oestrogen administered for 2 years and 7 months on average). In total, 210 implants were inserted, with $120(57.1 \%)$ placed in the mandible and 90 (42.9\%) in the maxilla. Premolars - 108 (51.8\%), and molars $59(28.1 \%)$ were most frequently replaced with implants, while the canine implants were the least frequent -16 (7.6\%). The number of incisor implants was 27 (12.9\%).

The implantation procedures were entirely successful in 81 patients (80.2\%), including 19 patients (18.8\%) without bone loss and 62 with bone loss not exceeding $25 \%(10-25 \%)$. The therapy was partially successful (bone loss greater than 25\%) in 6 patients (5.9\%), while in 14 patients (13.9\%) the treatment failed and implants were totally rejected.

In addition, the bone loss rates were assessed on the basis of implant location in the maxilla or mandible. It needs emphasizing that such bone losses are caused by implant loading and they may happen within the period of 3 to 6 months following the implantation. In 19 patients $(18.8 \%)$, no changes in the implant-surrounding bone tissue were found. In 16 patients (15.8\%), complete bone resorption was observed. A loss of $50 \%$ was detected in one patient, whereas in the remaining 65 patients $(64.3 \%)$ the bone loss ranged from 10 to $30 \%$.

\section{Assessment of bone loss around dental implants}

In the entire study group, the peri-implant bone loss rate was $15.8 \%$. No statistically significant differences were found between the female and the male groups $(Z=1.3 ; p=0.18)$ (Table I).

Figures $1 \mathrm{~A}$ and $\mathrm{B}$ show partial bone loss after implantation and after implant loading, respectively.

The study results indicated that gender $(p=0.18)$, age $(p=0.21)$, and menopausal status $(p=0.75)$ ex-

Tab. I. Bone tissue loss according to gender

\begin{tabular}{lccc}
\hline Bone tissue loss & $\begin{array}{c}\text { Women, } \\
n=71\end{array}$ & $\begin{array}{c}\text { Men, } \\
n=30\end{array}$ & $\begin{array}{c}\text { Total, } \\
n=101\end{array}$ \\
\hline None & $11(15.5 \%)$ & $8(26.7 \%)$ & $19(18.8 \%)$ \\
\hline Partial & $50(70.4 \%)$ & $16(53.3 \%)$ & $66(65.4 \%)$ \\
\hline Total & $10(14.1 \%)$ & $6(20 \%)$ & $16(15.8 \%)$ \\
\hline
\end{tabular}



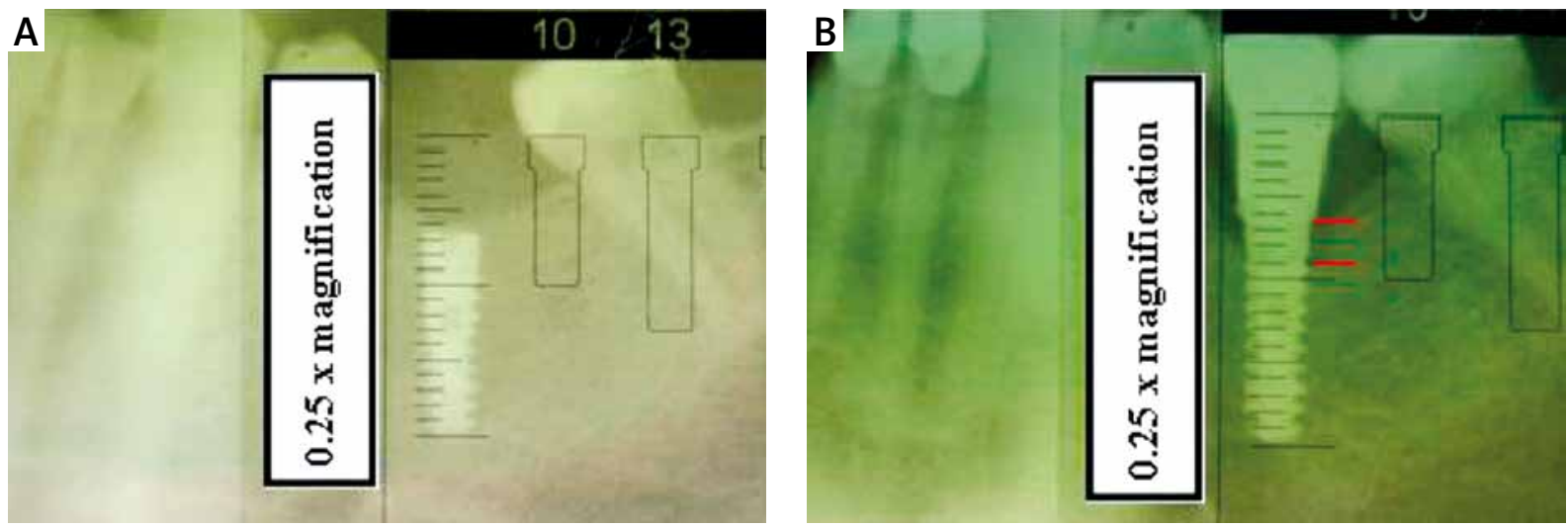

Fig. 1. A) X-ray taken immediately after the implant procedure. B) X-ray after implant loading with prosthetic superstructure. Peri-implant bone loss has been marked

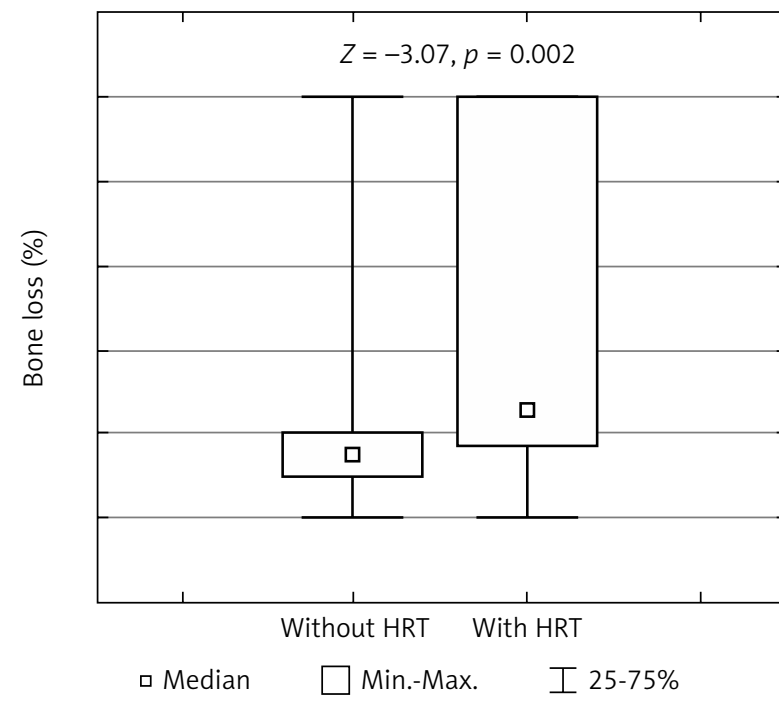

Fig. 2. Comparison of peri-implant bone loss in women with and without hormone replacement therapy (HRT)

erted no significant influence on the extent of peri-implant bone loss.

Furthermore, the examination of the effects of postmenopausal hormone replacement therapy on peri-implant bone loss showed that in the group of HRT-treated women, the average bone loss was 25\% (range: 17.5 $100 \%$ ); the bone loss in the group without HRT was lower - 15\% (range: 10-20\%). The differences were statistically significant $(p=0.002)$ (Fig. 2).

\section{Implant success rates evaluation}

The dental implantation procedure proved successful in 81 patients (80.2\%). The analysis of the relationship between bone loss and the success of the procedure, showed a statistically significant correlation among the variables $\left(\chi^{2}=91.9 ; p<0.0005\right)$. Despite partial bone loss (10-25\%), in thegreat majority of patients (above 90\%) dental implants osseointegrated and the procedures proved entirely successful.
Age $(p=0.5)$, gender $(p=0.2)$, and menopausal status $(p=0.99)$ were found to have no significant effects on the outcome of implant treatment.

Furthermore, the success rates of the procedures in the HRT-treated postmenopausal group were compared with those in the group not receiving HRT. The percentage of women with successful implant procedures was slightly lower in the HRT group compared with the group without HRT ( $75 \%$ vs. $92.9 \%$, respectively; $p=0.38$ ).

\section{Discussion}

Various authors point out that patients' age and sex do not exert any significant influence on implant acceptance $[5,6]$. Our findings confirmed that those parameters hardly affected the implantation success rate. In addition, the level of therapeutic success in our study was radically lower than that found in the multicentre study described by Lin et al. [7].

However, Sverzut et al. obtained different results. They found that the likelihood of early implant rejection increased each year by 1.075 and that men showed a 1.255 times greater risk of implant rejection than women [8]. According to August et al., this risk was higher in postmenopausal women when compared topremenopausal women and to men. The highest failure rate was observed in postmenopausal women receiving HRT $(13.6 \%)$ compared to premenopausal women (6.3\%) and to men older than 50 years of age (7.6\%); the differences were statistically significant $(p>0.05)$ [9]. Moy et al. showed that the patients' gender, unlike their age, did not have any major impact on the success of the implant procedure. The comparison of the younger group aged < 40 years with the group aged 60-70 years revealed higher risks of implant failure in older patients $(p<0.05)[10]$.

Some earlier studies looking at the correlation between oestrogen and progesterone levels and the successful osseointegration of dental implants revealed 
that periodic, menstruation-related hormone changes did not affect the healing process or implant osseointegration [11].

The deficiency of oestrogen and qualitative bone changes caused by menopause are probably the factors that hugely increase the risk of dental implant rejection [12]. Hormone replacement therapy substantially modifies the regenerative abilities of bone tissues, which may affect implant success rates in postmenopausal women. Our findings showed that postmenopausal women receiving hormone replacement therapy reported higher bone loss rates than those not receiving supplementation $(p=0.002)$. Likewise, the percentage of women with complete peri-implant bone loss was higher in the HRT group compared to women without hormone replacement therapy $(p=0.05)$.

The studies on the possible relation between hormone supplementation and the decrease in the osseointegration failure risk in postmenopausal women, conducted at the time when implants were introduced as a widely-used method of missing teeth treatment, showed that hormone replacement therapy did not exert any significant influence on the success of the implantation procedure in women [13].

Moreover, the study by Augusta et al. confirmed the correlation between hormone replacement therapy and the implant failure risk. The authors suggested that oestrogen replacement therapy could reduce the failure risk by about $41 \%$ in maxillary implants [9].

In contrast, Moy et al. demonstrated that oestrogen supplementation after menopause increased the risk of implant rejection. Gender, hypertension, coronary diseases, respiratory diseases and chemotherapy did not markedly increase the failure risk. Instead, there were factors like diabetes or radiation therapy of the head or neck. Implants inserted into the maxilla were more frequently rejected than those placed in the mandible. Patients over 60 years of age, with a history of diabetes or head and neck cancers, were found to show a higher risk of implant failure than healthy individuals [9].

\section{Conclusions}

Considering the fact that hormone replacement therapy contributes to greater peri-implant bone losses, HRT patients treated with dental implants should be informed about a greater risk of osseointegration failure, which may affect the success of implant therapy. It seems, however, that hormone replacement therapy is not a contraindication for dental implant procedures. A partial loss of bone tissue during implant osseointegration observed on radiographs is a common phenomenon concurrent with the regenerative processes of bones. It also has no influence onthe success of the procedure. A high number of implant rejection cases may be due to other factors, which calls for further investigation.

\section{Acknowledgements}

The present study was supported by a grant from the Medical University of Lublin, Poland (DS 122).

\section{Disclosure}

Authors report no conflict of interest.

\section{References}

1. Palma-Carrió C, Maestre-Ferrin L, Peñarrocha-Oltra D, et al. Risk factors associated with early failure of dental implants. A literature review. Med Oral Patol Oral Cir Bucal 2011; 16: 514-517.

2. Wojtowicz A, Jodko M, Perek J, Popowski W. Interactive 3D imaging technologies: application in advanced methods of jaw reconstruction using stem cells/pre-osteoblasts in oral surgery. Videosurgery Miniinv 2014; 9: 441-448.

3. Sakka S, Coulthard P. Implant failure: Etiology and complications. Med Oral Patol Oral Cir Bucal 2011; 16: 42-44.

4. Stupka M. Metody uzupełniania braku zębów rekonstrukcjami protetycznymi opartymi na wszczepach zębowych przy pomocy koron i mostów. Implantoprotetyka 2008; 32: 18-26.

5. Alsaadi G, Quirynen M, Komárek A, et al. Impact of local and systemic factors on the incidence of oral implant failures, up to abutment connection. J Clin Periodontol 2007; 34: 610-617.

6. Van Steenberghe D, Jacobs R, Desnyder $M$, et al. The relative impact of local and endogenous patient-related factors on implant failure up to the abutment stage. Clin Oral Implants Res 2002; 13: 617-622.

7. Lin Y, Li JH, Qiu LX, et al. A clinical retrospective study of years implant results. Chin J Stom Zhonghua Kou Qiang Yi Xue Za Zhi 2006; 41: 131-135.

8. Sverzut AT, Stabile GA, De Moraes M, et al. The influence of tobacco on early dental implant failure. J Oral Maxillofac Surg 2008; 66: 1004-1009.

9. August M, Chung K, Chang Y, et al. Influence of estrogen status on endosseous implant osseointegration. J Oral Maxillofac Surg 2001; 59: 1285-1289, discussion 1290-1291.

10. Moy PK, Medina D, Shetty V, et al. Dental implant failure rates and associated risk factors. Int J Oral Maxillofac Implants 2005; 20: 569-577.

11. Cuenin MF, Billman MA, Kudryk VL, et al. Estrogenic hormones and dental implant therapy: the effects of estrogen and progesterone levels on osseointegration of dental implants. Mil Med 1997; 162: 582-585.

12. Petkowicz B, Piotrkowicz J, Szeszko $Ł$, et al. Selected aspects of oral cavity diseases in menopausal women. Prz Menopauzalny 2013; 12: 352-357.

13. Minsk L, Polson AM. Dental implant outcomes in postmenopausal women receiving hormone replacement. Compend Contin Educ Dent 1998; 19: 859-862, 864. 